\title{
CONSIDERAÇÕES SOBRE O PROCESSO DE DESVERBALIZAÇÃO E DA CENARIZAÇÃ̃O NA TRADUÇÃO E INTERPRETAÇÃO DE UMA LÍNGUA ORAL PARA UMA LÍNGUA DE SINAIS
}

\author{
CONSIDERATIONS ON THE PROCESS OF DEVERBALIZATION AND \\ SCENARIZATION IN THE TRANSLATION AND INTERPRETATION FROM \\ AN ORAL LANGUAGE TO A SIGN LANGUAGE \\ CONSIDERACIONES SOBRE EL PROCESO DE DESVERBALIZACIÓN Y \\ CENARIZACIÓN EN LA TRADUCCIÓN E INTERPRETACIÓN DE UNA \\ LENGUA ORAL PARA UNA LENGUA DE SEÑALES
}

Giovana Bleyer Ferreira dos Santos *
Diego Maurício Barbosa

\section{Resumo}

O presente artigo tem como objetivo discorrer sobre algumas questões relacionadas ao processo de interpretação, como a desverbalização e a cenarização. Estudada por Seleskovitch, a desverbalização ocorre no momento em que o intérprete recebe as informações do texto na língua de partida e precisa decodificá-las para recriar o sentido apreendido na produção do texto na língua de chegada. A estratégia da cenarização, apresentada por Sophie Pointurier-Pournin, consiste em um mecanismo de auxílio para o intérprete, quando ele se encontra diante de restrições, como a do vazio lexical, ou precisa explicar conceitos mais complexos, que demandam mais do que a simples espacialização do discurso no espaço de sinalização. O trabalho apresenta considerações sobre o Modelo IDRC [Interpretação - Decisão - Recursos - Restrição] de Daniel Gile, que apresenta o processo de tradução como uma sucessão de fases de compreensão e de reformulação, nas quais o intérprete precisa lidar com os recursos e as restrições que lhe são impostos durante o processo.

Palavras-chave: Estudos da Interpretação. Interpretação de Língua de Sinais. Desverbalização. Cenarização. Modelo IDRC.

\footnotetext{
* Pós - Doutora em Letras e Linguística pela Universidade Federal de Goiás - UFG. Doutora em Estudos da Tradução pela Universidade Federal de Santa Catarina - UFSC. Mestre em Literatura e Práticas Sociais pela Universidade de Brasília - UNB. E-mail: giovanableyer@gmail.com

** Doutorando em Estudos da Tradução pela Universidade Federal de Santa Catarina UFSC. Mestre em Estudos da Tradução pela Universidade Federal de Santa Catarina. Professor do Departamento de Libras e Tradução da Faculdade de Letras da Universidade Federal de Goiás - UFG. E-mail: d.barbosa.tils@gmail.com
} 


\section{Introdução}

Os Estudos da Interpretação têm buscado entender um pouco mais sobre a tarefa de interpretar e sobre os fenômenos que ocorrem durante o processo. Pesquisadores de diferentes países - como Daniel Gile, que em 1999 foi pioneiro ao propor um "Modelo dos Esforços", discorrendo sobre esforços que se apresentam aos intérpretes durante seu trabalho, como o da memória de curto prazo —, têm se dedicado à compreensão dos processos vivenciados pelos intérpretes na preparação e execução de suas funções. Outro exemplo é o dos pesquisadores Robyn K. Dean e Robert Q. Pollard Jr. (2001) que aplicam a proposta de Karasek para o estudo de stress ocupacional sobre "Demanda e Controle" das línguas de sinais.

Dean e Pollard Jr., no artigo Application of Demand-Control Theory to Sign Language Interpreting: Implications for Stress and Interpreter Training (2001), observam que as "demandas" podem ser aplicadas a qualquer tipo de interpretação e se referem a questões que contribuem para um aumento na carga de stress do intérprete de língua de sinais. E o "controle" se refere ao poder que tem o indivíduo para agir sobre as demandas que a ele se apresentam. Como exemplo temos a demanda linguística, que se refere a aspectos como: fluência do cliente, tipo de discurso, habilidade de recebimento e produção do discurso pelo intérprete, vocabulário técnico, etc.

Dentro desse contexto, pretende-se discutir neste artigo alguns aspectos do trabalho do intérprete, relacionados à linguagem e ao modo de o intérprete recebê-la e reexprimi-la, a partir da desverbalização, proposta por Danica Seleskovich, e da cenarização, abordada por Sophie Pointurier-Pournin, um recurso útil aos intérpretes, quando querem inserir no espaço de sinalização elementos sugeridos pelo discurso. E também o modelo IDRH (Intérpretation - Décisions - Ressources - Contraintes) ${ }^{1} \mathrm{de}$ Daniel Gile, que discorre sobre as fases de compreensão e reformulação do discurso pelo intérprete.

\section{Os estudos da Interpretação}

Segundo Franz Pöchhacker (2004), os Estudos da Interpretação (EI) tiveram maior visibilidade a partir dos anos 70 e, desde essa época, os trabalhos de pesquisa tentam diferenciar a tradução da interpretação. Com base nesses estudos, Pöchhacker (2004, p. 11) define interpretação como "um tipo de tradução na qual a primeira e a 
última versão na outra língua é produzida com base em uma única apresentação de um enunciado na língua fonte" ${ }^{2}$. Isso implica que o intérprete tenha excelente domínio em ambas as línguas e culturas envolvidas, além de saber gerenciar, entre outras coisas, a memória de curto prazo, pois ela é acessada durante todo o processo tradutório. ${ }^{3}$ Pöchhacker (2004) menciona que a interpretação pode ocorrer entre diferentes línguas orais e também entre uma língua oral e uma língua de sinais, de modo consecutivo ou simultâneo. Neste artigo nos ateremos à interpretação, ocorrida simultaneamente entre uma língua oral e uma língua de sinais.

Outro importante ponto citado por Pöchhacker (2004, p.10) é que "a interpretação é realizada 'aqui e agora' para o benefício de pessoas que querem engajar na comunicação transpondo barreiras de língua e de cultura" ${ }^{4}$. No caso da interpretação simultânea, por exemplo, embora hoje já exista a prática do uso de meios tecnológicos como a transmissão da interpretação por imagem de vídeo, ela ocorre preferencialmente com as pessoas envolvidas dividindo o mesmo espaço. Isso acaba nos remetendo à importância do lugar que o intérprete deve ocupar durante a tarefa, visto que, em se tratando da interpretação que envolve uma língua de sinais, o espaço de sinalização é parte fundamental do discurso.

Ainda no que se refere aos Estudos da Interpretação, Pöchhacker (2004) destaca alguns autores que têm sido fundamentais para pensarmos as bases do desenvolvimento desse campo de estudo. Entre eles destacamos Danica Seleskovitch, que foi professora na École Supérier d'Interprètes et de tradutores (ESIT), Universidade de Paris IIISourbonne Nouvelle, onde criou um programa de doutorado em Tradutologia. As bases teóricas e metodológicas desse programa que Seleskovitch estabeleceu deram origem a diversas teses de doutorado sobre interpretação.

Entre os pesquisadores que seguiram os passos da Teoria interpretativa da Tradução o nome Marianne Lederer merece especial atenção. Juntamente com Seleskovitch, Lederer publicou uma coletânea de artigos sobre a formação de intérpretes, intitulada Interpréter pour traduire, que foi originalmente publicada em 1984. Esse livro, cuja reedição mais recente é de 2015, afirma seu lugar como uma obra de referência nos Estudos da Interpretação. E o professor e intérprete de conferências Daniel Gile, que ganhou notório reconhecimento ao publicar seu artigo "Testing the 
Effort Models' tightrope hypothesis in simultaneous interpreting - A contribution", publicado em 1999 e traduzido para o português do Brasil em 2015. ${ }^{5}$

Nesse artigo, Gile (2015) propõe o Modelo dos Esforços, que visa demonstrar o conjunto de esforços envolvidos durante a interpretação entre línguas orais, como: esforço de audição e análise; esforço de produção; esforço da memória de curto prazo e esforço de coordenação que, como o próprio nome diz, coordena os esforços mencionados anteriormente.

Gile (2015) analisa, também, a interpretação entre uma língua oral e uma língua de sinais e assim sugere que seja alterada a expressão "Esforço de Audição e Análise" para "Esforço de Recepção" com o objetivo de contemplar a interpretação entre línguas orais, que é prioritariamente oral/ auditiva, e as línguas de sinais que são visuoespaciais. O autor propõe que seja acrescido o Esforço de Autogestão no Espaço e Esforço de Interação com Receptores Surdos nas interpretações que envolvam uma língua de sinais.

No que se relaciona ao trabalho de Seleskovitch a pesquisadora Sophie Pointurier-Pournin, em sua tese de doutorado intitulada L'interpretation en Langue des Signes Française: contraintes, tactiques, efforts (A interpretação em Língua de Sinais Francesa: restrições, táticas e esforços) discorre sobre alguns pontos da Teoria Interpretativa da Tradução (TIT), desenvolvida por Seleskovitch na década de 60, que nos ajudam a compreender algumas questões sobre o processo de interpretação.

Pointurier-Pournin nos diz que um importante ponto da TIT é o fato de ela não se preocupar com a "busca de equivalências linguísticas" 6 (POINTURIER-POURNIN, 2014, p.17, tradução nossa), mas com o "sentido", com a situação comunicativa, que busca traduzir "o querer dizer do autor" 7 (POINTURIER-POURNIN, 2014, p.17, tradução nossa).

Para isso, é preciso que "o intérprete tenha uma boa bagagem cognitiva [...] que englobe o conjunto de conhecimentos linguísticos e extralinguísticos do intérprete sobre o sujeito, seu conhecimento de mundo e a compreensão do contexto no qual ele intervém" ${ }^{8}$ (POINTURIER-POURNIN, 2014, p.17, tradução nossa). Ou seja, como já mencionado, o intérprete precisa ter domínio das línguas e das culturas de partida e de chegada para realizar o trabalho, visto que ele exerce o papel de mediador.

Outro ponto sobre a TIT, mencionado por Pointurier-Pournin (2014), que remete diretamente à necessidade de o intérprete ter "uma boa bagagem cognitiva" é a 
aplicação do termo desverbalização (deverbalization), criado por Seleskovitch. Segundo Pointurier-Pournin (2014, p.18, tradução nossa) a desverbalização "implica que o processo de interpretação se faz em diversas fases: fase de compreensão $\rightarrow$ fase de desverbalização $\rightarrow$ fase de reformulação" 9 . A TIT, portanto, encoraja "a análise do discurso para uma melhor apropriação do sentido pelo intérprete" (POINTURIERPOURNIN, 2014, p.18, tradução nossa) ${ }^{10}$. E ao reelaborar o discurso no contexto de chegada, o intérprete deve estar atento às "necessidades comunicativas inerentes a situação" 11 (POINTURIER-POURNIN, 2014, p.18, tradução nossa). Ou seja, o intérprete tem autonomia para reelaborar o discurso na transferência de uma língua para outra, reafirmando seu poder de mediador, mas é necessário que as duas línguas envolvidas sejam bem conhecidas por ele, para a realização do trabalho.

Buscando ampliar a visão sobre o processo interpretativo nos dias de hoje, Pointurier-Pournin associa a teoria de Seleskovitch à teoria de Skopo, de Vermeer, e à de Gile (2014), sobre o modelo IDRC. Para Pointurier-Pournin (2014) a função de comunicar deve estar sempre presente no processo de tomada de decisões para uma interpretação, o que é feito considerando-se as normas dos sistemas de partida e de chegada e as questões culturais inerentes a cada língua durante a reformulação da mensagem.

\title{
2. O modelo IDRC de Daniel Gile
}

Para melhor discutir o processo tradutório, apresentamos abaixo o Modelo IDRC de Daniel Gile (2009), que também é exposto por Pointurier-Pournin em sua tese:

\section{Modelo IDRC}

TEXTO DE PARTIDA

\author{
$\downarrow$
}

RECURSOS

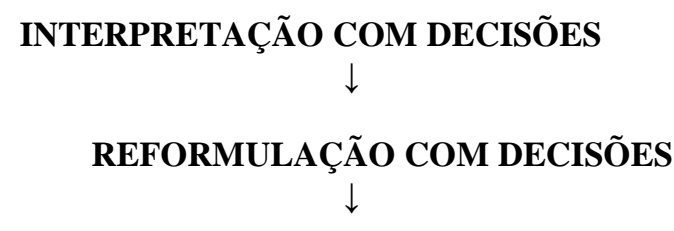

RESTRIÇÕES

TEXTO DE CHEGADA 
Segundo Gile (2009, p.74, tradução nossa), o modelo "esquematiza o processo de Tradução em uma sucessão de fases de compreensão e de reformulação" ${ }^{12}$. E, como sugere o esquema apresentado acima:

Após cada fase de compreensão, o segmento relevante do Texto de partida é interpretado com os recursos existentes e as decisões são tomadas. Após a fase de reformulação, as decisões interveem na escolha das palavras e das estruturas linguísticas a serem empregadas, e também na seleção das informações que serão guardadas, que serão modificadas, que serão acrescidas de explicação novamente, dependendo dos recursos e das restrições, incluindo as especificações do cliente, os conhecimentos que parecem razoáveis de serem atribuídos aos leitores ou auditores da tradução, etc.. ${ }^{13}$

Para melhor esclarecer seu modelo IDRC, Gile (2009) discorre sobre quatro de suas características. Em primeiro lugar, o autor destaca que o modelo é descritivo, que "pode acolher reflexões sobre todas as categorias da Tradução humana" 14 (GILE, 2009, p.74, tradução nossa). Em segundo, Gile afirma que se trata de um "modelo de processo e não de um produto" ${ }^{15}$ (2009, p.74, tradução nossa). Isso implica que ele não deve ser analisado do ponto de vista de uma "linguística comparativa", mas de uma "Traduçãoação", o que pode esclarecer a presença de restrições e a existência de certos recursos na tomada de decisões. A terceira característica, segundo Gile (2009) diz respeito ao conceito de interpretação (do texto de partida) e está relacionado às pesquisas realizadas na área de psicolinguística, mais especificamente às operações cognitivas envolvidas nesse processo de transferência de uma língua para outra, que envolve "reconhecimento de unidades linguísticas a partir de sinais visuais ou sonoros na interpretação gramatical de frases" ${ }^{16}$ (GILE, 2009, p.74-75, tradução nossa). E a quarta, diz respeito às decisões tomadas pelo tradutor que, para Gile (2009), ocupa lugar central em seu modelo.

Gile (2009) afirma que, ao interpretar os signos linguísticos, o tradutor passa por um processo de decisões que engloba uma escolha entre os diversos potenciais linguísticos aos quais ele tem acesso. O resultado de sua tradução será um discurso adaptado às necessidades inerentes à realidade do momento. $\mathrm{O}$ produto, que referenciamos aqui como texto de chegada (conceito aplicado de maneira ampla e se estendendo, portando, a um discurso oral ou produzido em língua de sinais), será adequado ao conhecimento dos receptores do texto de chegada sendo, porém, equivalente ao texto de partida em se tratando do sentido do discurso a ser transmitido. 
Além dessas características do modelo IDRC, Gile (2009) também discorre sobre as restrições a que o tradutor pode ser submetido durante o ato de tradução. Essas restrições se relacionam à limitação de recursos que ele enfrenta durante o processo tradutório. Entre essas restrições temos "a inferioridade de conhecimentos temáticos pertinentes do Tradutor" (GILE, 2009, p.77, tradução nossa) ${ }^{17}$. Isso implica uma sobrecarga cognitiva durante $\mathrm{o}$ ato tradutório, em especial no ato interpretativo simultâneo, pois o intérprete não tem acesso a outras fontes de pesquisa para a obtenção de dados que poderiam auxiliá-lo como: dicionários, consulta a especialistas sobre o tema, etc. Isso poderá acarretar dificuldades na produção do texto na língua de chegada. Essas dificuldades estão relacionadas ao que Gile (2009, p. 77, tradução nossa) classifica como "limites de habilidades sociais, comunicativas, linguísticas e cognitivas do Tradutor" ${ }^{18}$. Para ele, as restrições, em qualquer uma dessas áreas, afetarão a capacidade do intérprete contornar problemas advindos da falta de estratégias para fazer a mediação linguística-cultural, demandada para a elaboração do discurso na língua de chegada, em atividades como a interpretação simultânea, que necessita um bom uso da memória de curto prazo.

Outras duas restrições discutidas por Gile (2009) são: a alta carga cognitiva a que o intérprete está exposto, como apresenta em seu "Modelo dos esforços" ${ }^{19}$, e a submissão a determinadas normas expostas pelo cliente ou mesmo pelo tipo de discurso a ser traduzido, que pode conter traços estilísticos e culturais marcantes, ou possuir caráter religioso ou mesmo judicial. Isso impede o intérprete de produzir certas explicitações, sob o risco de comprometer a idoneidade da mensagem. Em termos gerais, podemos dizer então que tanto o tradutor quanto o intérprete estão sujeitos a restrições que podem interferir na produção do texto na língua de chegada. E quanto maiores forem seus conhecimentos linguísticos e extralingüísticos, mais chances terão de realizar o processo de desverbalização, que permitirá ao texto na língua de chegada ter sentido equivalente ao texto da língua de partida.

A boa bagagem cognitiva do intérprete e suas estratégias diante das restrições vão demonstrar, como ressalta Pointurier-Pournin (2014, p. 65-66, tradução nossa), que ele "toma parte no desenvolvimento da conversação gerando (apesar de si mesmo) as decisões da fala, colocando as palavras e os não ditos respeitando as normas sociais dos diferentes participantes com o objetivo de manter a comunicação" ${ }^{20}$. 


\section{O uso da paráfrase e da cenarização na Interpretação}

Tendo discorrido sobre a importância do intérprete como mediador durante a desverbalização no processo tradutório; sobre o fato de que ele está sujeito a influências enquanto esse processo ocorre e de que muitas vezes o modo de ocorrência é simultâneo, expomos abaixo algumas questões relacionadas às estratégias que podem auxiliá-lo durante esse processo: a paráfrase e a cenarização.

Como as línguas de sinais são visuoespaciais, é no espaço que acontece a organização da língua. Pointurier-Pournin (2014) afirma que, para a construção do sentido no espaço, entra em jogo o próprio corpo do intérprete, pois "o corpo inteiro do intérprete de língua de sinais se torna o principal vetor da mensagem ${ }^{21}$ " (POINTURIERPOURNIN, 2014, p.148, tradução nossa), visto que praticamente todos os seus movimentos serão interpretados como linguísticos. Em se tratando da construção do sentido no espaço de sinalização, a autora destaca estratégias utilizadas pelo intérprete para essa criação: a paráfrase e a cenarização. Segundo Pointurier-Pournin (2014, p.88, tradução nossa), a paráfrase é utilizada sempre que,

[...] uma palavra procurada na língua de chegada não está disponível para o intérprete por muitas razões (esquecimento, sobrecarga cognitiva, falta de conhecimentos linguísticos específicos, vazio lexical) ou ainda quando uma frase inteira requer uma contextualização particular no discurso traduzido ${ }^{22}$.

A utilização desse recurso "contribui para a afirmação de que tudo pode ser dito em língua de sinais quando em uma situação dialógica" ${ }^{23}$ (Pointurier-Pournin, 2014, p.148, tradução nossa). Conforme demonstra a autora, "a utilização pertinente do espaço permite que as entidades no espaço de sinalização sejam colocadas em evidência e que se criem, por conseguinte, interações entre esses espaços que permitirão ao locutor a criação do sentido" 24 (POINTURIER-POURNIN, 2014, p. 90, tradução nossa). Pointurier-Pournin refere-se ao recurso da cenarização, termo criado por SéroGuillaume, como uma das principais táticas observadas na interpretação em Língua de Sinais, pois seu uso permite que o intérprete represente,

[...] no espaço de sinalização uma parte do discurso que pode comportar uma só palavra ou muitos segmentos consecutivos, sem ser seguido palavra por palavra pelos elementos do enunciado mas buscando representar visualmente o conteúdo do discurso. Sua 
colocação em cena requer uma rápida conceitualização do termo ou do discurso pelo intérprete para pôr em cena em seu espaço de sinalização todas as principais interações possíveis do sentido do discurso querido pelo orador ${ }^{25}$ (POINTURIER-POURNIN, 2014, p.93-94, tradução nossa).

Em outras palavras "a cenarização acontece quando o intérprete cria uma cena dinâmica entre os elementos (pessoa, coisa, conceito) que não existe no discurso original mas cujos referentes são bem presentes no discurso correspondente em LS" 26 (POINTURIER-POURNIN, 2014, p.225, tradução nossa). Isso porque, segundo a autora, a cenarização consolida uma transferência, a saber, ela projeta o sentido da mensagem que está desverbalizada para adquirir sentido na língua de chegada. A projeção desta mensagem ocorre no espaço de sinalização. Pointurier-Pournin (2014, p.223, tradução nossa) destaca que, em se tratando de uma cenarização,

[...] há três possibilidades de transferência: a transferência pessoal (o locutor se torna a entidade da qual ele está falando, pessoa, coisa, animal); a transferência de tamanho ou forma (o locutor descreve uma coisa por sua forma, altura, etc.) e a transferência de situação (a situação é representada no espaço de sinalização) ${ }^{27}$.

É preciso saber distinguir entre a tática de espacialização (que acontece naturalmente pela própria característica da língua) e a cenarização. Na espacialização os elementos da frase são postos no espaço para gerar valor de sentido pela interação, que pode corresponder à própria estrutura gramatical da frase. A cenarização ocorre quando “o intérprete cria uma cena dinâmica entre os elementos (pessoa, coisa, conceito) que não exista no discurso original, mas cujos referenciais estão bem presentes no discurso em LS correspondente, na intenção de exprimir o sentido e de 'mostrar' as idéias" ${ }^{28}$ (POINTURIER-POURNIN, 2014, p.225, tradução nossa).

Como forma de ilustrar o processo, a autora discorre sobre a cenarização da seguinte frase "os dicionários unilíngues são utilizados apenas quando os dicionários bilíngues não tem nada a oferecer" ${ }^{29}$ (POINTURIER-POURNIN, 2014, p.236, tradução nossa). Na representação da cenarização ela cita um exemplo de sua pesquisa, em que o intérprete posiciona o tradutor, um dicionário bilíngue e um dicionário unilingue, na cenarização. Ele fez com que o tradutor fosse primeiramente ao dicionário bilíngue e, 
dando a entender que ele não encontrou o que procurava, dirigiu-se ao dicionário unilíngue.

Pela frase, era possível inferir a figura do tradutor no discurso, embora ele não tivesse sido, de fato, mencionado. A sua inserção na cenarização tornou compreensível a discussão sobre os dicionários sem que houvesse discrepância no sentido da mensagem em sua reelaboração no texto da língua de chegada. Ou seja, "a cenarização permite ao intérprete representar no espaço de sinalização uma parte do discurso vocal, sem seguir os elementos do enunciado palavra por palavra, mas procurando representar visualmente seu conteúdo" 30 (POINTURIER-POURNIN, 2014, p.226, tradução nossa).

\section{A Cenarização na Tradução e Interpretação de Português para Libras}

Para uma reflexão sobre o processo de cenarização na tradução e interpretação de Língua Portuguesa e Língua Brasileira de Sinais, buscamos exemplos reais de: (A) tradução de contos. Disponíveis em (http://www.bibliolibras.com.br); (B) Interpretações realizadas no $5^{\circ}$ Congresso Nacional de Pesquisa em Tradução e Interpretação de Libras e Português, que ocorre a cada dois anos na Universidade Federal de Santa Catarina UFSC, disponíveis em (https://repositorio.ufsc.br/handle/123456789/174517). Optamos por estes recortes, devido à disponibilidade dos materiais, com acesso livre na internet.

A análise ocorreu com o auxilio do software EUDICO Linguistic Annotator (ELAN), que permite criar sistemas de anotação em vídeos, possibilitando a investigação da Libras, que é uma língua visuoespacial, e da Língua Portuguesa Brasileira, de forma simultânea. Analisamos primeiramente a tradução de Português para Libras de contos dos irmãos Grimm e não houve ocorrências de cenarização. As hipóteses para isso são: (1) estudos prévio do material e (2) lag time restrito pela filmagem, gerando maior simultaneidade.

$\mathrm{Na}$ análise da interpretação de Português para Libras, no decorrer dass Interpretações realizadas no Congresso da UFSC, foram observados 2 intérpretes. $\mathrm{Na}$ produção do intérprete A não houve ocorrências de cenarização, mas na produção do intérprete B identificamos alguns exemplos. A hipótese para esse fato é de que a opção de realizar a cenarização interfere diretamente do fluxo de informações interpretadas. Dessa forma, se o intérprete optar por essa estratégia, ele deve ter ciência de que algumas informações poderão ser perdidas na interpretação caso não controle o tempo 
destinado à cenarização. Os exemplos identificados na produção do intérprete $\mathrm{B}$ foram os seguintes ${ }^{31}$ :

Exemplo 1, em língua portuguesa: “então ele tem que ser chamado à responsabilidade. Se o ensino for feito de uma forma adequada, ele terá um ambiente que vai facilitar, terá um professor que estará funcionando como um facilitador”. Interpretação para a Libras: "a responsabilidade não deve ser minha (professor) deve ser dele (aluno) [a competência tradutório - (interpretação da frase anterior)] eu (professor) não estarei dando autonomia para ele (aluno). Eu (professor) não posso entregar tudo pronto, ele (aluno) precisa ter essa responsabilidade também".

Figura 1 - Registro da cenarização pela ferramenta ELAN (Exemplo 1).

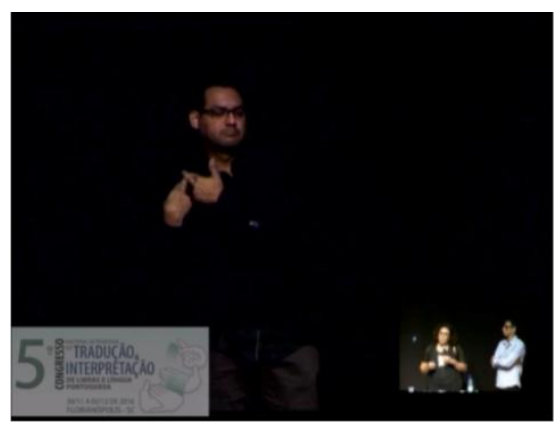

No exemplo acima o intérprete optou pela cenarização, criando uma interação entre os elementos que posicionou no espaço e que, como podemos dizer, estavam sugeridos pelo discurso. Nessa criação não houve perda de informação em relação à mensagem em Língua Portuguesa, mas sim uma clarificação da mensagem no contexto de chegada, mantendo-se, porém, o sentido pretendido pelo discurso de partida.

Exemplo 2, em língua portuguesa: "nós queremos um professor construtivista e queremos um aluno construtivista também”. Interpretação para Libras: “eu, como professor, acredito no construtivismo e construo (o conhecimento) com a ajuda do aluno e isso vai acontecendo de forma dinâmica e com o meu incentivo".

Figura 2 - Registro da cenarização pela ferramenta ELAN (Exemplo 2). 


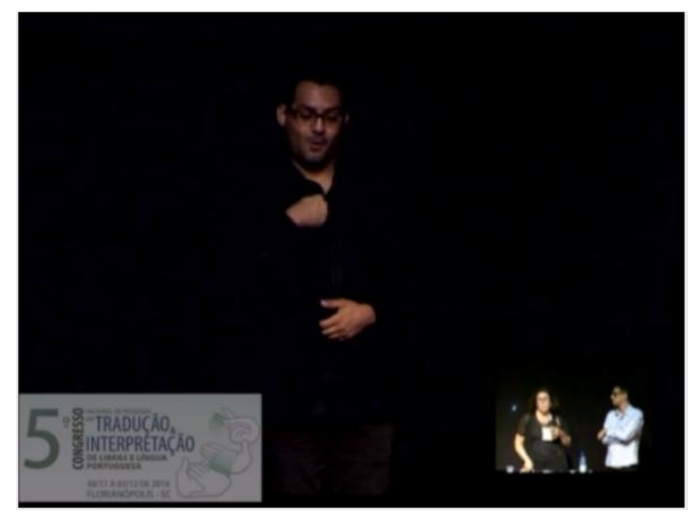

Assim como no exemplo anterior, tem-se também a cenarização. O intérprete optou por mudar as pessoas do discurso, inserindo o professor e o aluno, sugeridos pelo discurso, no espaço de sinalização, criando interação entre eles. Essa cenarização não causou perda de informação do segmento seguinte do discurso tendo apenas clarificado o sentido exposto no discurso de partida.

\section{Conclusões}

Os Estudos da Interpretação têm procurado entender um pouco mais sobre a tarefa de interpretar e também sobre os fenômenos que ocorrem durante o processo. Neste sentido, o objetivo deste trabalho foi apresentar alguns elementos recorrentes na interpretação em língua de sinais. Para tal, apontamos Seleskovitch (1975) que propõe a “Teoria do Sentido" da Interpretação; Gile (2009) com o Modelo IDRC [Interpretação Decisão - Recursos - Restrição] e Pointurier-Pournin (2014) que discute a cenarização como uma possível estratégia durante a interpretação entre uma língua oral e uma língua de sinais.

A cenarização, como um fenômeno incipiente dentro dos Estudos da Interpretação, mereceu um pouco mais de atenção nesta análise, para que pudéssemos identificá-la identificar esse elemento também na interpretação entre Língua Portuguesa e Língua Brasileira de Sinais.

Ao retomar alguns apontamentos identificados nas análises, verificamos que, no contexto de tradução dos contos da Bibliolibras, analisamos 2 contos de aproximadamente 12 minutos cada e neles não foi identificada a produção de cenarização. No contexto de conferência, foram analisados os trabalhos de 2 intérpretes e a cenarização foi identificada somente na produção de um deles. 
Na tradução, como observado, não identificamos a cenarização e as hipóteses para o fato são: (1) o tradutor estudou previamente o texto a ser traduzido e durante o processo de estudo já fez as escolhas que ele julgou serem as melhores para o seu público-alvo; (2) por serem traduções filmadas, a câmera e o tempo de filmagem limitaram a acréscimo de algum recurso durante a tradução.

$\mathrm{Na}$ interpretação, podemos inferir que o profissional teve mais liberdade, dentro do lag time (tempo de atraso em relação à língua fonte), de utilizar os recursos disponíveis para deixá-lo o mais claro possível para o público-alvo. Uma questão inquietante neste caso é: por questão de tempo, quando o intérprete opta por utilizar um recurso como a cenarização ele esta abrindo mão de interpretar uma informação que virá a seguir, ou seja, algo será perdido durante esse processo.

Com base nesses dados, podemos sugerir que futuras pesquisas sejam desenvolvidas e que um número maior de contextos seja contemplado, pois pudemos ver que na tradução, que envolva algum tipo de registro (neste caso o vídeo), dificilmente identificaremos esse recurso. Pointurier-Pournin (2014) ressalta que a utilização da cenarização demanda um grande domínio de recursos do intérprete, visto que, além de demandar um excelente controle da "memória de espacialização ${ }^{32}$ " (POINTURIER-POURNIN, 2014, p. 236, tradução nossa) é preciso que tenha uma excelente bagagem cognitiva. Isso porque deverá pensar rapidamente em estratégias que lhe permitam gerar um texto de chegada com a mesma carga de sentido do texto de partida sem que haja perda significante de algum segmento do discurso de partida durante seu trabalho de cenarização.

Assim como a paráfrase, a cenarização mostra-se um recurso muito útil como estratégia na interpretação, especialmente diante de restrições como o vazio lexical, o uso de metáforas e a necessidade de melhor discussão sobre conceitos apresentados no texto de partida.

\begin{abstract}
This article aims at discussing some issues related to the interpretation process, such as Deverbalization (Seleskovitch 1975), which must occur when the interpreter receives the information from the source text and needs to decode it (de-verbalize it) in order to re-create sense in the process of production of the target text. This work also presents Daniel Gile's IDRC [Interpretation - Decision - Resources - Restriction] Model, which
\end{abstract}


clarifies that the translation process is composed of a succession of stages of comprehension and reformulation in which the interpreter must deal with the resources and constraints that are imposed to him during the proceedings. This article also presents the strategy of scénarisation, discussed by Sophie Pointurier-Pournin in her doctoral thesis. According to Pointurier-Pournin, the scénarisation functions as a mechanism of aid to the interpreter when he is faced with constraints such as the lexical emptiness or when he needs to explain more complex concepts that demand more than the simple spatialization of speech in the signaling space.

Key-words: Interpreting Studies. Interpreting Sign Language. Deverbalization. IDRC' Model. Scénarisation.

\section{Resumen}

El presente artículo tiene el objetivo de reflexionar sobre algunas cuestiones relacionadas al proceso de interpretación, como la desverbalización y la cenarización. Estudiada por Seleskovich, la desverbalización sobreviene en el momento en el que el intérprete recibe las informaciones del texto en la lengua de partida y necesita decodificarlas para recrear el sentido aprendido en la producción del texto en la lengua de llegada. La estrategia de la cenarización, presentada por Sophie Pointurier-Pournin, consiste en un mecanismo de ayuda para el intérprete, cuando se enfrenta a restricciones, como la del vacío lexical, o necesita explicar conceptos más complejos, que demandan más que la simple especialización del discurso en el espacio de señalización. El trabajo presenta observaciones sobre el Modelo IDRC [Interpretación Decisión - Recursos - Restricción] de Daniel Gile, que presenta el proceso de traducción como una sucesión de fases de comprensión y de reformulación, en las que el intérprete tiene que trabajar con los recursos y con las restricciones que se le imponen durante el proceso.

Palabras-clave: Estudios de la Interpretación, Interpretación de Lengua de Señales. Desverbalización. Cenarización. Modelo IDRC.

\section{Referências}

BIBLIOLIBRAS. Goiânia: Universidade Federal de Goiás, Faculdade de Letras, Biblioteca Infantil e Juvenil Bilíngue Libras-Português, 2017. Disponível em: http://www.bibliolibras.com.br Acesso em: 1 nov 2017

DEAN, R.K., POLLARD, Jr.. Application of demand-control theory to sign language interpreting: implications for stress and interpreter training. Pub Med.gov. J Deaf Stud Educ, 2001. Disponível em: https://www.ncbi.nlm.nih.gov/pubmed/15451859. Acesso em: 1 nov 2017. 
GILE, Daniel. "Testing the Effort Models' Tightrope Hypotesis in Simultaneous Interpreting - A contribution”. Hermes, Journal of Linguistics, volume 23, p. 153 172, 1999. Disponível em:

https://www.researchgate.net/publication/289204277_Testing the_Effort_Models\%27 Tightrope_Hypothesis_in_Simultaneous_Interpreting_-_A_Contribution.

Acesso em: 1 nov. 2017

GILE, Daniel. "Le modele IDRC 'Interprétation-Décisions- Ressources-Contraintes' de la Traduction: une optique didactique". In: LAPLACE, COLETTE, MARIANNE LEDERER \& DANIEL GILE (eds). La traduction et ses métiers: aspects théoriques et pratiques. Cahiers Champollion n. 12. Caen: Lettres Modernes Minard. 2009. p.73-86. Disponível em: http://docplayer.fr/8714263-Le-modele-idrc-interpretationdecisions-ressources-contraintes-de-la-traduction-une-optique-didactique.html.

Acesso em: 1 nov. 2017.

GILE, Daniel, “Testando a hipótese da 'corda bamba' do modelo dos esforços na interpretação simultânea - uma contribuição". Tradução: WEININGER, Markus J; SANTOS, Giovana B. F.; BARBOSA, Diego Maurício. Florianópolis: Cadernos de Tradução, 2015.

PÖCHHACKER, Franz. Introducing Interpreting Studies. London and New York: Routlegde, 2004.

SELESKOVITCH, D. Langage, langues et mémoire: étude de la prise de notes en interprétacion consécutive. Paris: Minard, 1975.

SELESKOVITCH, D; LEDERER, Marianne. Interpréter pour traduire. Paris: Didier Érudition, 1984.

POINTURIER-POURNIN, Sophie. L'interprétation en Langue des Signes Française: contraintes, tactiques, efforts. Linguistique. Université Paris 3 - Sorbonne Nouvelle, Thèse de doctorat en traductologie, 2014. Disponível em: https://tel.archivesouvertes.fr/tel-01077924/document . Acesso em 10 set 2017.

REPOSITÓRIO INSTITUCIONAL DA UFSC, Campus Florianópolis, Centro de Comunicação e Expressão, Libras, V Congresso Nacional de Pesquisas. Disponível em: (https://repositorio.ufsc.br/handle/123456789/174517). Acesso em: 1 nov 2017.

\section{NOTAS}

\footnotetext{
${ }^{1}$ Interpretação - Decisão - Recursos - Restrição.

2 [...] a form of Translation in which a first and final rendition in another language is produced on the basis of a one-time presentation of an utterance in a source language.
} 
${ }^{3}$ Em relação à nomenclatura utilizada, esclarecemos que consideramos o processo interpretativo um processo tradutório e que o intérprete é um tradutor.

4 [...] interpreting is performed 'here and now' for the benefit of people who want to engage in communication across barriers of language and culture.

${ }^{5}$ Para maiores informações ver o artigo de GILE, Daniel, “Testando a hipótese da 'corda bamba' do modelo dos esforços na interpretação simultânea - uma contribuição". Tradução: WEININGER, Markus J.; SANTOS, Giovana Bleyer F. dos; WEININGER , Markus J.; SANTOS, Giovana Bleyer F. dos; BARBOSA, Diego Maurício. Florianópolis: Cadernos de Tradução, 2015

${ }^{6}[\ldots]$ a recherche d'équivalences linguistiques.

7 [...] sens [...] le vouloir dire de l'auteur.

${ }^{8}[\ldots]$ l'interprète de posséder un bagage cognitif [...]. Ce bagage cognitif englobe l'ensemble des connaissances linguistiques et extralinguistiques de l'interprète sur le sujet, sa connaissance du monde et la compréhension du contexte dans lequel il intervient.

9 “[...] implique que le processus de l'interprétation se fait en plusieurs phases: une phase de compréhension, une phase de déverbalisation et une phase de reformulation".

10 [...] l'analyse du discours pour une meilleure appropriation du sens par l'interprète..

$11[\ldots]$ en fonction des besoins de communication inhérents à la situation.

12 [...] schématise le processus de Traduction en une succession de phases de compréhension et de reformulation".

${ }^{13}$ Lors de chaque phase de compréhension, le segment de Texte de départ concerné est interprété avec les ressources existantes et des décisions sont prises. Lors de la phase de reformulation, des décisions interviennent dans le choix des mots et des structures linguistiques à employer, mais aussi dans la sélection des informations que l'on gardera, que l'on modifiera, que l'on ajoutera par explicitation, là aussi en fonction des ressources et des contraintes, y compris le cahier des charges du client, les connaissances qu'il semble raisonnable d'attribuer aux lecteurs ou auditeurs de la traduction, etc.

${ }^{14}[\ldots]$ peut accueillir des réflexions sur toutes les categories de la Traduction humaine.

15 [...] il s'agit d'un modèle de processus et non pas de produit.

16 [...] reconnaissance d'unités linguistiques a partir de signaux visuels ou sonores et dans l'interprétation grammaticale des phrases.

${ }^{17}$ L’infériorité des connaissances thématiques pertinentes du Traducteu.

${ }^{18}$ Les limites des habilités sociales, communicatives, linguistiques et cognitives du Traducter.

${ }^{19}$ Para maiores informações ver o artigo de GILE, Daniel, “TESTANDO A HIPÓTESE DA 'CORDA BAMBA' DO MODELO DOS ESFORÇOS NA INTERPRETAÇÃO SIMULTÂNEA - UMA CONTRIBUIÇÃO”. Tradução: WEININGER, Markus J.; SANTOS, Giovana Bleyer F. dos; BARBOSA, Diego Maurício. Florianópolis: Cadernos de Tradução, 2015.

20 [...] prend part au déroulement de la conversation en gérant (malgré lui) les prises de parole, en mettant en mots des non-dits tout en respectant les normes sociales attendues de lui par les différents intervenants dans le but de maintenir un niveau de communication . 
${ }^{21}[\ldots]$ le corps entier de l'ILS devient le principal vecteur du message e le corps entier de l'ILS devient le principal vecteur du message.

22 Lorsqu'un mot recherché en langue d'arrivée n'est pas disponible chez l'interprète pour plusieurs raisons (oubli, surcharge cognitive, manque de connaissances linguistiques spécifiques, vide lexical) ou bien lorsqu'une phrase entière requiert une recontextualisation particulière dans le discours traduit.

${ }^{23}[\ldots]$ il est possible de tout dire en langue des signes puisqu'en situation dialogique.

${ }^{24}$ L'utilisation pertinente de l'espace permet de mettre en place des entités dans l'espace de signation et de créer ensuite des interactions entre ces espaces qui permettront au locuteur de créer du sens

${ }^{25}$ La scénarisation est une des tactiques principalement observées en interprétation en LS. Elle permet à l'interprète de représenter dans l'espace de signation une partie du discours qui peut comporter un seul mot ou plusieurs segments consécutifs, en ne suivant pas les éléments de l'énoncé mot à mot mais en cherchant à représenter visuellement le contenu du discours. Sa mise en place requiert une conceptualisation rapide du terme ou du discours par l'interprète pour mettre en scène dans son espace de signation toutes les interactions possibles aboutissant au sens du discours voulu par l'orateur .

${ }^{26}$ Nous parlerons de scénarisation lorsque l'interprète crée une scène dynamique entre des éléments (personne, chose, concept) qui n'existent pas dans le discours original mais dont les référents sont bien présents dans le discours en LS

${ }^{27}$ On compte trois possibilités de transferts: le transfert personnel (le locuteur devient l'entité dont il parle, personne, chose, animal); le transfert de taille ou de forme (le locuteur décrit une chose par sa forme, hauteur, etc.) et le transfert de situation (la situation est représentée dans l'espace de signation).

${ }^{28}[\ldots]$ lorsque l'interprète crée une scène dynamique entre des éléments (personne, chose, concept) qui n'existent pas dans le discours original mais dont les référents sont bien présents dans le discours en LS correspondant, dans l'intention d'en exprimer le sens et d'en 'montrer' les idées.

${ }^{29}[\ldots]$ que les dictionnaires unilingues sont utilisés que quand les dictionnaires bilingues n'ont rien donné.

${ }^{30}$ La scénarisation permet à l'interprète de représenter dans l'espace de signation une partie du discours vocal, en ne suivant pas les éléments de l'énoncé mot à mot, mais en cherchant à représenter visuellement son contenu.

${ }^{31}$ Nos exemplos apresentamos a transcrição do discurso em Língua Portuguesa e tradução livre da Libras, que pode apresentar parênteses ou colchetes quando necessário explicitar algo implícito nas frases que serão tomadas como exemplos.

${ }^{32}[\ldots]$ mémoire de la spatialisation . 